\title{
Introductory Editorial: Moving Forward
}

We are very pleased and excited to begin leading a talented, energetic and well-respected group of associate editors at Renewable Agriculture and Food Systems. We know that they will help us continue to publish a premier scientific journal focusing on the science underpinning an economically, ecologically and socially sustainable agriculture and food system. In addition, Renewable Agriculture and Food Systems relies upon the expertise and judgment of its reviewers to maintain the high standard of research it publishes. The names of the over 100 people who reviewed articles for the journal in 2011 can be found at: http://journals.cambridge.org/action/displayJournal? jid=RAF. We know that acting as a reviewer involves significant time and effort, and we very much appreciate their efforts. Without them, the quality of the journal could not be sustained.

We would like to take this opportunity to thank John Doran for his service to the journal over the past decade and more. As his final editorial demonstrated, he has a long and successful history with the journal and many accomplishments for which he can be proud. Thanks also to outgoing Associate Editors Molly Anderson (21 years of service for the journal), Mark Liebig ( 9 years, including Forum Editor) and John Ryan (9 years) for their service to the journal.

As incoming Editor-in-Chief, I wanted to tell you a bit about myself. I am a Professor of Sociology at Clarkson University in Potsdam, New York. I earned a PhD in Rural Sociology from Cornell University in 1995, an MS in Food and Resource Economics from the University of Florida in 1988, and a BA in Economics from The College of William \& Mary in 1983. Previously, I was a policy analyst for the Henry A. Wallace Institute for Alternative Agriculture and the Director of the Sustainable Agriculture Research and Education (SARE) Program for the Southern Region. In addition, I have worked for the Foreign Agricultural Service on its food aid programs and served as a Peace Corps Volunteer in the Philippines.

The incoming Assistant Editor-in-Chief is Lydia Oberholtzer. She is a senior researcher with Penn State's Agricultural Economics and Rural Sociology department. She has worked on organic and small farm marketing issues for many years, and was previously with the Henry A. Wallace Institute for Alternative Agriculture. Her expertise is in local and organic food marketing and supply chains, food systems and access, small farm marketing (especially farmers' markets and CSA), as well as surveys and qualitative research.

To us, sustainable agriculture is not a regime of practices or regulations. It is a philosophy, a social movement and a set of economic, ecological and scientific principles simultaneously. In that vein, a sustainable agrifood system embodies several fundamental principles. These include biological complexity at the farm and landscape levels; diversity in the structure of production, processing and distribution systems; and reducing environmental impacts and protecting animal welfare at all stages of the food system. It also means the provision of safe, satisfying and nutritious food to all consumers, while providing sustaining livelihoods to farm and non-farm workers. The long view of history has shown convincingly that intensiveness and productivity is more resilient and effective when embedded within this type of social, economic and ecological framework. In addition, it has become clear that the global public will support, through policy and purchasing, this type of system. Therefore, one of our primary goals as incoming editors is to assist firms of all types, governments, non-governmental organizations, scientists and individuals around the world to transform their food systems toward sustainability as we have defined it.

Toward that end, we are excited about the current themed issue on conservation tillage and organic agriculture. As the guest editors indicate, the articles cover approaches to organic no-till agriculture in North America, and organic reduced till in conservation tillage in Europe. They conclude that,

\footnotetext{
Multi-disciplinary teams of scientists and organic farmers are needed to solve the problems that are encountered when tillage is reduced or eliminated, and organic cash crops are grown. Our hope is that collaborations among those interested in this topic will be spurred as a result of this special issue, including trans-Atlantic efforts between European and North American researchers.
}

This dovetails with our vision of science as a vehicle for supporting an economically, ecologically and socially sustainable agriculture and food system. In addition, we have included in this issue an article on conservation agriculture in smallholder systems in Laos to highlight the importance of smallholder systems to contribute to a sustainable agriculture; but also to emphasize our commitment to a global reach for the journal.

Rick Welsh

Editor-in-Chief

Lydia Oberholtzer Assistant Editor-in-Chief 